SOMTSH MEDICAL JOURNAL VOLUME $287 \quad 2$ JULY 1983

PRACTICE OBSERVED

\section{Solving Problems}

\section{Access to physiotherapy services}

J BAHRAMI, M HAMID HUSAIN, SUE CLIFTON, MIKE PRINGLE, F E HILL,
DAVID W L RICHARDS

The mortality and morbidity from all sorts of conditions vary
widely among the regions in Britain, which is 8 matter for
both study and concern. Furchermore, the N National Health

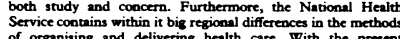
Service conatins whthin it big regional differences in the methods
of orgnising and delivering health care. With the present
Department of Health and Social Security policy of devolving

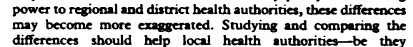
differences should help local health authorities - be they
regional or district heasth authorities, family practitioner commintees, or even individual practices - to arrive at betret
ways of organising and delivering health care, which is the idea behind this article and others that we hope will follow.
we have started with the probiem of how best to provide general practitioners' patients with physiocherapy. In Bradford

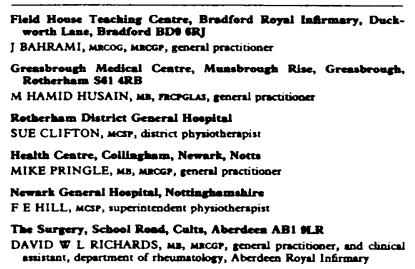

\section{How can phydiocherapy best be provided for the
patients of general practidioners?}

the district medical liaison commintee has decided that a cach casc referered for physiocherapy. Not far away in Rotherham 作

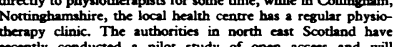
mobaty conducted a pilot study of open access and will because they are now considering introducing direct access to
physioberapy services for all the general practionerers. Each pecial local conditions with which it must contend, but a look

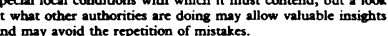

Bradford

J BAHRAM

At the first meeting of our district medical liaison comminitece
the manin item on the agenda was "direct access to physiotherepy by general practitioners." To many this may sound like an
outdated issue, hardly worthy of consideration at the first outdated issuc, hardlyy worthy of consideration at the first
meting of this august committec. After all, it is common mowiedge that $76 \%$ of districts provide community physio-
therapy and $66 \%$ allow general practitioners direct access to

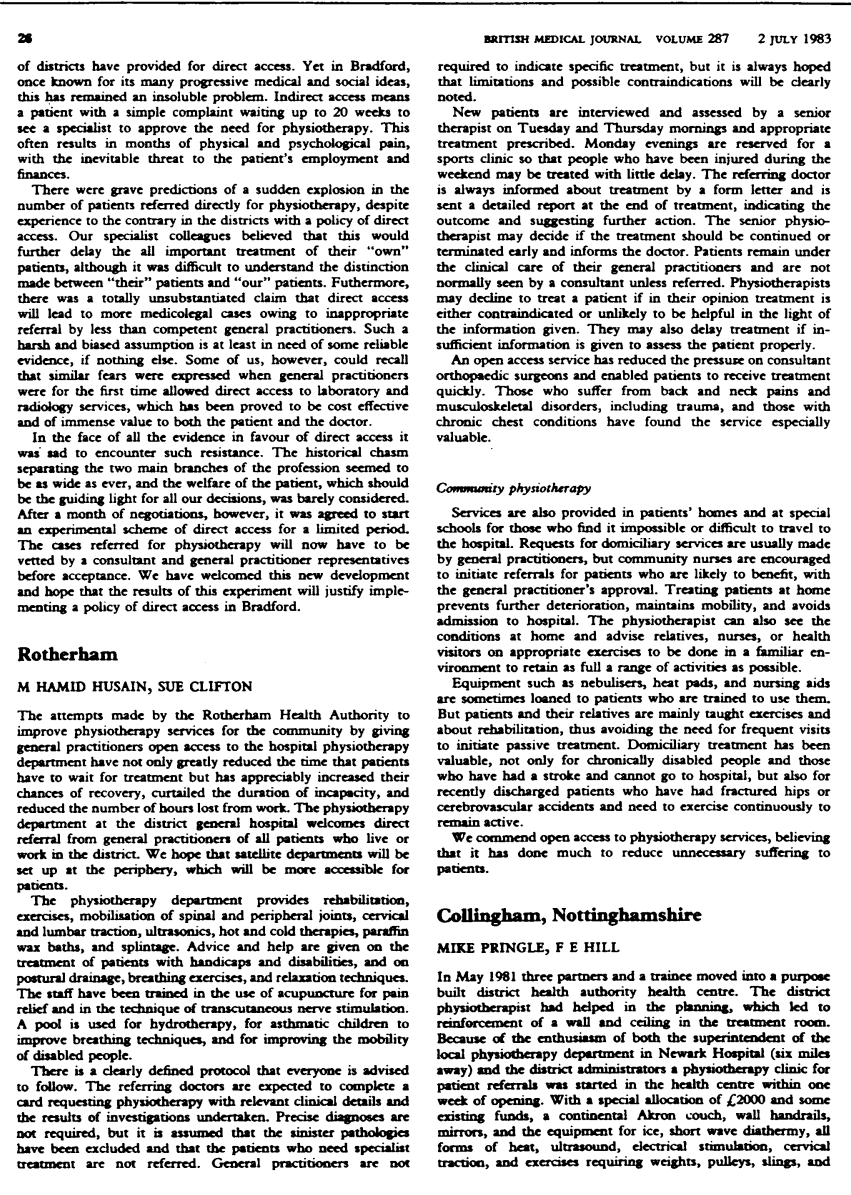

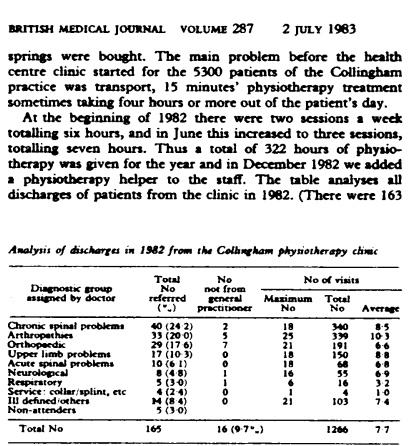
from nine to 24 a month, the busiest month becing June with
169 treatments. The new referals from Colline

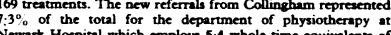

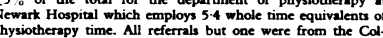

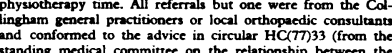
standing medical committee on the relationship berween the
medical profession and the remedial profession, 1977).

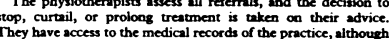
They have access to the medical records of the practice, althought
they do not write in them. Consumales, such as collers, wrist braces, epicondylitis clasps, and walking sticks, are supplied
from the physiotherapy department at Newark Hospital, and from the physiotherappy department at Newark Hospitial, and
rome patients need to have their treatment transferred there, some patients need to have their treacturent transferred there,
or indeed to be seen in their own homes. Patients who have
problems in getting to the healch centre have used the volunturty

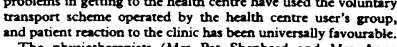
and patient reaction to the clinic has becen universally favourable.
The physiotherapists (Mrs Par Shephard and Mrs Anne
Burs)

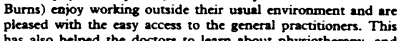
the quality of their referrals has improved. Moreover, patients,
physiotherapists, and doctors have benefited from the ability

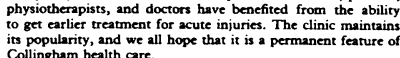

North east Scotland

DAvID W L RICHARDS

Open access to physiotherapy services has long been considered
in north acsus Scoctand, and a pilot strudy has been carried out

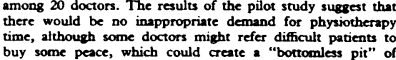

new referrals, but discharges allow a better measurement of
duration of treatment.) The number of

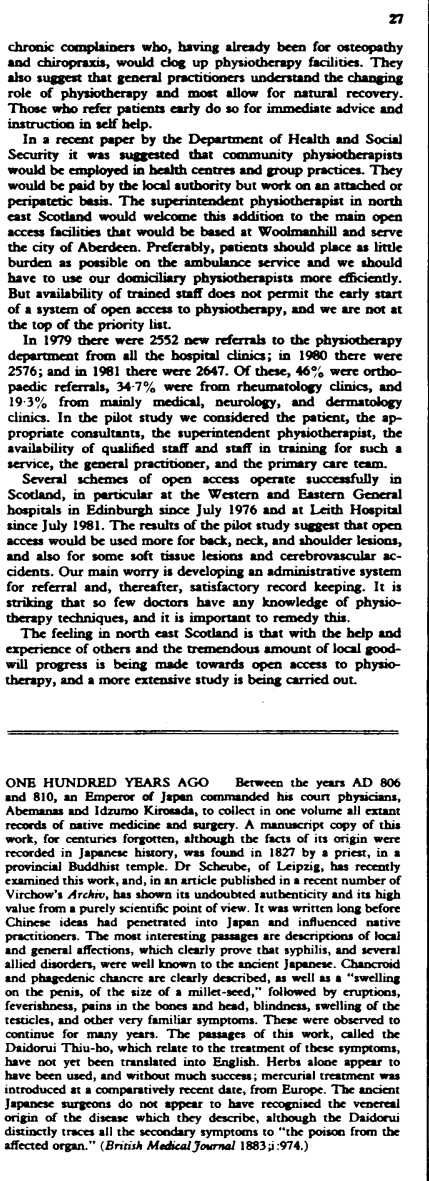

$\underline{\underline{\sigma}}$ BRTTISH MEDTCAL JOURNAL VolUME $287 \quad 2$ JULY 198

\section{Practice Research}

Out of hours calls in general practice: does the doctor's attitude alter patient demands?

TERENCE CUBITT, GABRIELA TOBIAS

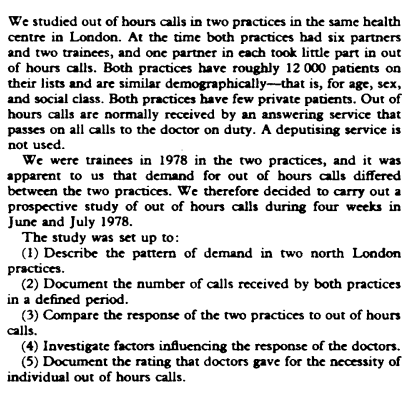

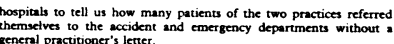
Results

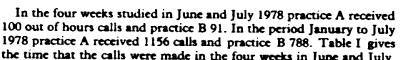

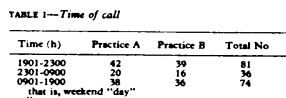

AGE AND Sx OF PATIRTS Method

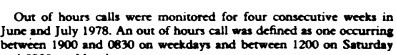

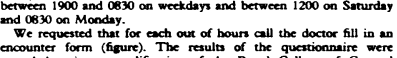

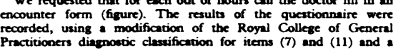

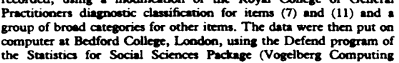

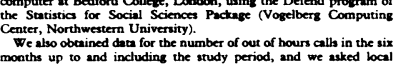

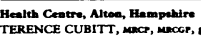
Well Stroet Surgery, well Street, Loodon Es Correpondence to: Dr Cubitr 